\title{
Empirical Analysis of Monetary Transmission in Tunisia: What do SVAR Models Tell Us?
}

\author{
Samuel Bates ${ }^{*}, 1$ and Ahmed Hachicha ${ }^{2}$ \\ ${ }^{1}$ SDFi Universite Paris-Dauphine, Place Maréchal De Lattre de Tassigny, 75016 Paris, France \\ ${ }^{2}$ URED Faculté des Sciences Économiques et de Gestion de Sfax, Route de l'aérodrome km 4.5,3018 Sfax, Tunisie
}

\begin{abstract}
Monetary policy contributes to stabilize growth. Particularly in a reforming context for financial and economic activities, it is important to know how central bankers' decisions through the short term interest rate of the money market are transmitted to the real variables: the GDP and the inflation. Few studies on monetary transmission mechanisms deal with the Maghreb countries. Structural VAR are used to investigate the importance of various monetary transmission channels at a macro scale from convenient impulse response functions. As a result, the Tunisian central bank should mainly target inflation, focussing the interest rate channel and the long-term interest rate as the principal transmission variable.
\end{abstract}

Keywords: Impulse responses function, inflation, output, transmission channels, SVAR modelling.

\section{INTRODUCTION}

Monetary policy must guarantee a steady environment for growth. Various channels transmit the decision of central bankers to the real sphere. Theoretically, thanks to the famous survey in the Journal of Economic Perspectives (Bernanke and Gertler [1], Meltzer [2], Mishkin [3], Taylor [4]), we can schematize monetary transmission mechanism as a network of linkages going from the monetary policy instrument to its targets on the real sphere (inflation and output gap) through intermediate variables (the transmission variables).

Our analysis highlights the effects of short-term and long-term interest rate shock on both targeted variables - the inflation rate and the gross domestic product $(\mathrm{G} d p)$ - through traditional transmission variables such as the long-term interest rate, the cost credit, the volume credit and the exchange rate. Opposite to other channels that need an effective fluctuation in the monetary policy instrument, announcement effects influence the real sphere only through the threat of the central bank intervention. In this way, the announcement effects channel deserves a specific treatment and will not be considered in the application.

Monetary policy is useful to obtain a stable macroeconomic environment in favor of a steady growth. When the economic context is characterized by reforms influencing the financial as well as the real sphere, it is a great importance to better know the ways central bankers' decisions are transmitted to the real variables. However, there are few studies on monetary transmission mechanisms that deal with the Maghreb countries like Chaabane and Hachicha [5]. These developing countries face several mutations. Until the early

*Address correspondence to this author at the SDFi Universite ParisDauphine, Place Maréchal De Lattre de Tassigny, 75016 Paris, France; Tel: +33 (0) 144054 947; E-mail: Samuel.bates@dauphine.fr 1980s, Algeria, Morocco, and Tunisia - albeit to different degrees - pursue inward-looking economic development strategies emphasizing a key role of national regulator institutions in order to accelerate the economic development.

In Tunisia, steps to enhance competition among banks have accelerated since 1986 from measures enlarging the scope of activities for foreign banks into the domestic economy. Offshore banks can: collect deposits from residents, finance some resident firms acting in the productive sector, extend credits in local currency from deposits collected from residents, and engage medium and long-term lending in foreign exchange as well as finance resident import and export. These changes theoretically permit to increase the amount of domestic credit to finance productive investments and durable consumption.

Besides, Tunisia's reform efforts also included a gradual liberalization of interest rates except for interest rates on lending to priority sectors in the developing strategy. In 1987, interest rates on term deposits of at least three months are liberalized and rates on special savings accounts are pegged to the money market rate (MMR) of the preceding month. Lending rates, except those to priority sectors, are allowed to be set freely within a spread of 3 percentage points above the MMR. In 1990, preferential rates are increased for all priority sectors, albeit only moderately for the agricultural sector. In 1994, lending rates for non-priority sectors are completely liberalized, and in late 1996 preferential interest rates for priority sectors are abolished. The requirement for prior authorization of loans by the Central Bank is eliminated in 1988. In 1994, the banks obligation to subscribe to and hold treasury bills is abolished. Obligatory sectorial lending ratios are suppressed in late 1996, along with preferential refinancing rates. It is worth noting that most deposit and lending rates in Tunisia are indexed on the MMR, i.e., deposit rates remain fixed to at most 2 percent on sight deposits and MMR minus 2 percent for savings deposits. 
All these changes are in line with fluid liquidity circuit. Morocco and Tunisia have made important progress over the last decade toward establishing a sound bank intermediation, deepening their financial markets, mobilizing domestic financing, and using indirect market-based monetary policy instruments.

Nevertheless, in many respects, their financial sectors still fall short of achieving the dynamism, efficiency, and depth of full-fledged market-based financial systems in industrial countries or in the most advanced developing countries. This reflects the fact that some of the key reforms are implemented only partially while others are introduced only recently and therefore have not yet produced their full impact. In this case, it is convenient to identify how the monetary policy can find their positive impacts improving a more stable macroeconomic environment. Considering the ongoing economic mutations and owing to the lack of empirical studies, a better knowledge of monetary transmission is a contribution of a great importance for the central banking activity. Choosing Tunisia as an example, the asset prices channel cannot be analysed because of the lack of data. Anyway, in this empirical analysis, one question finds its answer. Which transmission channels are effective and base the choice of intermediary targets for the monetary policy to create a monetary regulation favourable to a steady growth?

The paper is organized as follows. After a detailed presentation of the empirical method, we report and comment the results for the Tunisian case. To conclude, we get some lessons for the Tunisian monetary policy considering it is one of the first analyses in the field for a Maghreb country.

\section{EMPIRICAL METHOD}

The Structural VAR (SVAR) methodology has become a widely useful tool in the analysis of the monetary transmission mechanisms. SVAR models provide a certain mix between atheoretical method and approach coherently based on economic theory as defined in Fry and Pagan [6].

Because economic interpretations of reduced form VAR equations do not take into account the information in the medium and long run, we adopt SVARs and use eligible economic theory and econometric considerations to impose the structure of the system. In this class of models, identification especially focuses on the errors of the system, which are interpreted as linear combinations of exogenous shocks.

Our empirical approach is based on a VAR, which is partitioned into two types, i.e. the standard SVAR AB model of Amisano and Giannini [7] and the SVAR model of Blanchard and Quah [8]. The purpose is to quantify the effects of each channel at short term and long term separately.

As in Mehrotra [9], a reduced form VAR model can be written as:

$\mathrm{Z}_{t}=\mathrm{A}_{l} \cdot \mathrm{Z}_{t-1}+\ldots+\mathrm{A}_{q} \cdot \mathrm{Z}_{t-q}+\mathrm{C} \cdot \mathrm{D}_{t}+\mathrm{u}_{t}$

where $q$ denotes the order of the VAR model. $\mathrm{Z}_{t}=\left(\mathrm{Z}_{1 t}, \ldots\right.$, $\left.\mathrm{Z}_{k t}\right)^{\prime}$ is a $(\mathrm{k} \times 1)$ random vector, $\mathrm{A}_{i}$ are fixed $(\mathrm{k} \times \mathrm{k})$ coefficient matrices. $\mathrm{C}$ is the coefficient matrix associated with the possible deterministic terms $\mathrm{D}_{t}$. $\mathrm{u}_{t}$ is a k dimensional white noise process. The structural representation of (1) can be expressed as:

$$
\mathrm{A} \cdot \mathrm{Z}_{t}=\mathrm{A}_{1}{ }^{*} \cdot \mathrm{Z}_{t-1}+\ldots+\mathrm{A}_{p}{ }^{*} \cdot \mathrm{Z}_{t-p}+\mathrm{C}^{*} \cdot \mathrm{D}_{t}+\mathrm{B} \cdot \varepsilon_{t}
$$

Here, the structural errors are assumed to be white noise, the coefficient matrices are different from the reduced form coefficients in (1). The matrix A allows modelling the instantaneous relations while B is a structural form parameter matrix. The structural shocks $\varepsilon_{t}$ are related to the model residuals by linear restrictions. Omitting deterministic terms, the equation (2) is written as follows because they are unaffected by impulses hitting the system and do not affect such impulses:

A . $\mathrm{Z}_{t}=\mathrm{A}_{l}{ }^{*} \cdot \mathrm{Z}_{t-1}+\ldots+\mathrm{A}_{p}{ }^{*} \cdot \mathrm{Z}_{t-p}+\mathrm{B} \cdot \varepsilon_{t}$

In order to link both reduced and structural forms, we multiply (3) with $\mathrm{A}^{-1}$, whereby $\mathrm{A}_{p}=\mathrm{A}^{-1} \cdot \mathrm{A}_{p}{ }^{*}(\mathrm{p}=1, \ldots, \mathrm{N})$. According to Breitung, Bruggemann and Lütkepohl [10], the relation between the reduced form disturbances and the structural form innovations is expressed as:

$\mathrm{u}_{t}=\mathrm{A}^{-1} \cdot \mathrm{B} \cdot \varepsilon_{t}$

and

$\Sigma_{u}=\mathrm{A}^{-1} \cdot \mathrm{B} \cdot \mathrm{B}^{\prime} \cdot \mathrm{A}^{-1^{\prime}}$

$\Sigma_{u}$ is the maximum likelihood estimator of the reduced form model.

To estimate, we use the maximum likelihood from a scoring algorithm as in [7] or [10]. It is worth noting that if the algorithm does not converge, some manual fine-tuning may be necessary.

If an over-identified model is estimated, the following expression computes the value of a likelihood ratio statistic:

$\mathrm{LR}=\mathrm{T} \cdot\left(\log \left|\Sigma_{u}{ }^{r}\right|-\log \left|\Sigma_{u}\right|\right)$

$\Sigma_{u}{ }^{r}$ is the equivalent estimator $\Sigma_{u}$ from the restricted structural form estimation.

In the Blanchard and Quah model $A=\mathrm{I}_{k}$ and the matrix of long run effects $\left(\mathrm{I}_{k}-\mathrm{A}_{l}-\mathrm{A}_{2}-\mathrm{A}_{p}\right)^{-1}$. B is assumed to be a lower triangular.

The impulse responses are computed from the estimated VAR coefficients, and the Hall percentile interval is chosen to build confidence intervals $(\mathrm{C} I)$ that reflect the estimation's uncertainty:

$$
\mathrm{CI}=\left[\phi_{1}-\mathrm{t}^{*}{ }_{(1-\gamma / 2)}, \phi_{2}-\mathrm{t}^{*}{ }^{2}\right]
$$

where $\mathrm{t}^{*} / 2$ and $\mathrm{t}_{(1-\gamma / 2)}$ respectively are the $\gamma / 2$ and the $(1-\gamma / 2)$ quantiles of the distribution of $\mathrm{CI}=\left[\phi_{1}-\phi_{2}\right]$ (see Hall [11]).

$0.5 .\left(k^{2}+k-1\right)$ restrictions have to be imposed for the identification of the system.

\section{Choice of Variables}

To capture the interest rate, the credit channel (in volume and in cost) and the exchange rate channel of the monetary policy, several macroeconomic variables are needed.

Stir defines the short-term interest rate of the money market as an indicator of the change in the monetary policy. 
According to Ganev, Molnar, Rybinski and Wozniak [12], it is inappropriate to choose a monetary aggregate. Indeed, it plays a less significant role in the monetary transmission particularly in the case of developing countries.

In term of monetary transmission variables, Ltir is the long-term interest rate. It is proxied by the 10 years government bond yields. The lending rate $(\mathrm{Lr} r)$ measures the credit cost and Dcred represents the amount of domestic credit to the private sector. These last two variables are necessary to capture the lending and the balance sheet channels that both operate through transmission mechanisms in terms of credit cost and volume. Rer is the real effective exchange rate useful to include the exchange rate channel in the analysis. As the exchange rate channel depends on the price fluctuations registered by the main commercial partners in relation to the home prices, the interest of Rer consists of implicitly taking into account the international trade structure of the country. Indeed, Rer is the nominal exchange rate weighted by the ratio of the external price index on the local one. Especially, Tunisian growth is driven by strong domestic and European demands, and other recent diversified sources. In its computation, Rer places a wider importance on the prices of the main commercial partners that influence the external value of the national currency through international trade.

$\mathrm{G} d p$ and $\mathrm{P}$ (the inflation rate) are the two monetary policy targets on the real sphere. $\mathrm{P}$ is measured from the consumption prices index.

From January 1988 to June 2007, the monthly data come from DataStream and the Tunisian central bank. They are converted in millions of constant dollars (basis 2000) and transformed in order to work in logarithm.

To deal with each monetary transmission, each estimated system includes three endogenous variables among the aforementioned list of variables: the control variable of the monetary policy (Stir), one intermediate variable between the monetary and the real sphere i.e. the transmission variable (Ltir or L $r$ or Dcred or Rer), and one target $\mathrm{G} d p$ or P.

Therefore, the mathematical writing of errors for both reduced and structural forms of the 8 estimated VAR are reported in Table $\mathbf{1 .}$

Table 1. Residuals in the VAR

\begin{tabular}{|c|c|c|}
\hline Error & $\begin{array}{l}\text { Transmission } \\
\text { Channel }\end{array}$ & $\begin{array}{c}\text { Target on the Real } \\
\text { Sphere }\end{array}$ \\
\hline$u_{t}^{l}=\left(u_{t}^{\mathrm{S} t i r}, u_{t}^{\mathrm{L} t i r}, u_{t}^{\mathrm{G} d p}\right)^{\prime}$ & Interest rate & $\mathrm{G} d p$ \\
\hline$u_{t}^{2}=\left(u_{t}^{\mathrm{S} t i r}, u_{t}^{\mathrm{L} t i r}, u_{t}^{\mathrm{P}}\right)^{\prime}$ & Interest rate & $\mathrm{P}$ \\
\hline$u_{t}^{3}=\left(u_{t}^{\mathrm{S} t i r}, u_{t}^{\mathrm{L} r}, u_{t}^{\mathrm{G} d p}\right)^{\prime}$ & Cost credit & $\mathrm{G} d p$ \\
\hline$u_{t}^{4}=\left(u_{t}^{\mathrm{S} t i r}, u_{t}^{\mathrm{L} r}, u_{t}^{\mathrm{P}}\right)^{\prime}$ & Cost credit & $\mathrm{P}$ \\
\hline$u_{t}^{5}=\left(u_{t}^{\text {Stir }}, u_{t}^{\text {Dcred }}, u_{t}^{\text {Gdp }}\right)^{\prime}$ & Credit in volume & $\mathrm{G} d p$ \\
\hline$u_{t}^{6}=\left(u_{t}^{\text {Stir }}, u_{t}^{\text {Dcred }}, u_{t}^{\mathrm{P}}\right)^{\prime}$ & Credit in volume & $\mathrm{P}$ \\
\hline$u_{t}^{7}=\left(u_{t}^{\mathrm{S} t i r}, u_{t}^{\mathrm{Rer}}, u_{t}^{\mathrm{G} d p}\right)^{\prime}$ & Exchange rate & $\mathrm{G} d p$ \\
\hline$u_{t}^{8}=\left(u_{t}^{\text {Stir }}, u_{t}^{\text {Rer }}, u_{t}^{\mathrm{P}}\right)^{\prime}$. & Exchange rate & $\mathrm{P}$ \\
\hline
\end{tabular}

The corresponding structural disturbances are identical with $\varepsilon$ instead of $u$.
To respect the theoretical assumptions concerning each transmission mechanism, the SVAR methodology suggests imposing restrictions only on the contemporaneous structural parameters so that reasonable economic structures might be derived (Kim and Roubini [13], Leeper and Roush [14], Mojon and Peersman [15], Dedola and Lippi [16]).

\section{RESULTS AND IMPLICATIONS IN THE TUNISIAN CASE}

From the Augmented Dickey-Fuller and Phillips-Perron tests, all series are integrated of order 1 . In appendix, we report results of the estimated parameters for the whole SVAR systems.

Following Benkwitz, Lütkepohl and Wolters [17], some small sample properties of bootstrap confidence intervals are better in comparison to other asymptotic methodologies. Bootstrap percentile $95 \%$ confidence intervals are computed to illustrate parameter uncertainty. The percentile method proposed in $[11,17]$ is used with 1000 replications. The horizon of all responses is 60 months. Figs. (1-4) represent the impulse response functions of the targets on the real sphere $(\mathrm{G} d p$ and P) after a shock on the short-term interest rate.

Focussing on significant responses higher than $1 \%$ in the Figs. (1-4), the impact of a restrictive monetary policy is the following:

* There is no identifiable long-term impact on the real sphere. It points out that it is harder to anchor inflation and output dynamics on specific targets consistent with a good monetary regulation. To stabilize the real sphere, controlling the short-term influences of monetary shocks is of utmost importance.

* The output is less reactive than the inflation to monetary shocks. As a consequence, an inflation target should be privileged in the monitoring of the Tunisian monetary policy.

* There is no exchange rate transmission mechanism extended enough to pay attention to Rer as an intermediate variable for the monetary policy. The unsteady history of the Tunisian exchange rate regime does mitigate this conclusion. The lack of exchange rate transmission channel mainly originates from the floating but administrated exchange rates in an emergency of instability. Presently, Tunisia is in a transition period after a long period of administered exchange rates. Thus, the exchange rate does not play yet a predominant role in amplifying monetary policy actions.

However, since 2001 Tunisian authorities intervene in the market to alleviate the volatility of real exchange rate against a basket of currencies to encourage competitiveness. Furthermore, The central bank lets the dinar (Tunisian national currency) depreciates by more than it is required to keep the real exchange rate constant in order to partially offset the impact of reduced external protection on competition. But, this exorbitant devaluation will certainly influence the inflation in level. To curve imported inflation, monetary 
Short-term responses
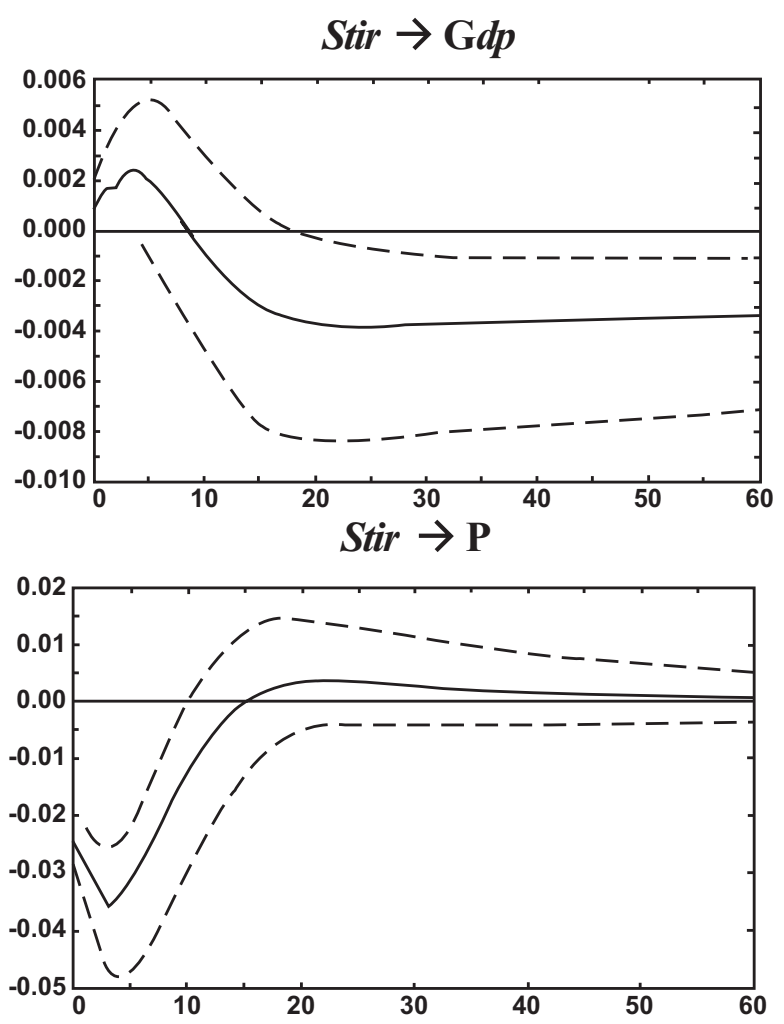

Fig. (1). Impulse response functions (Transmission variable: Ltir).

\section{Short-term responses}
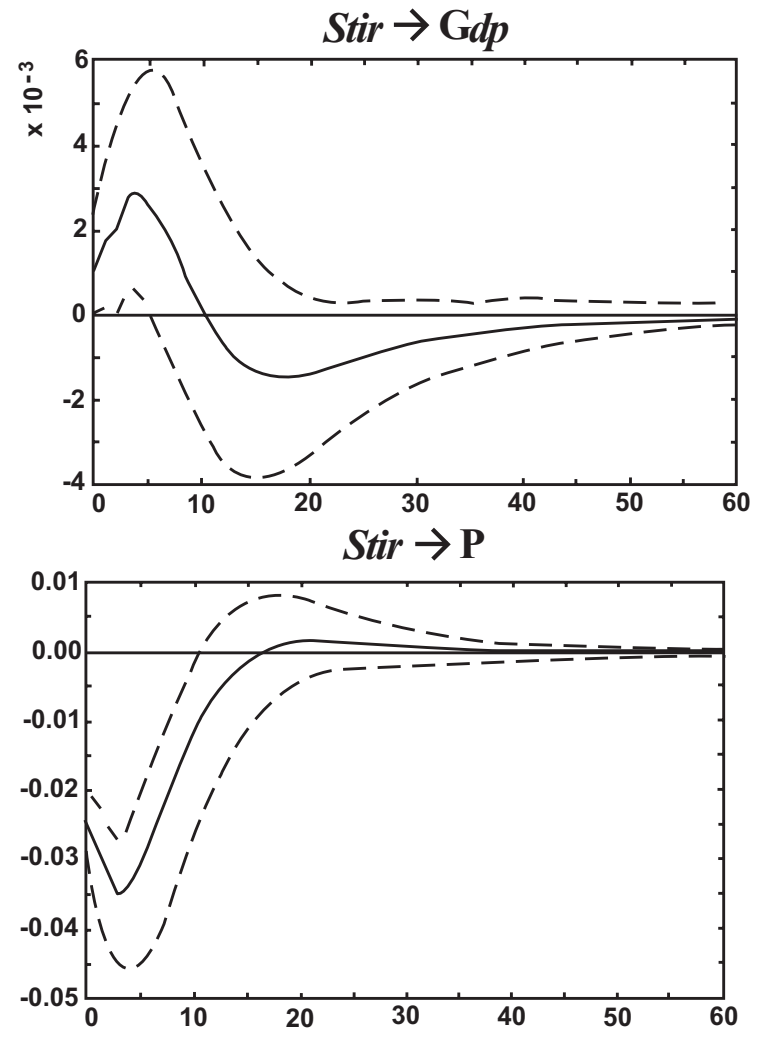

\section{Long-term responses}

Stir $\rightarrow$ Gdp
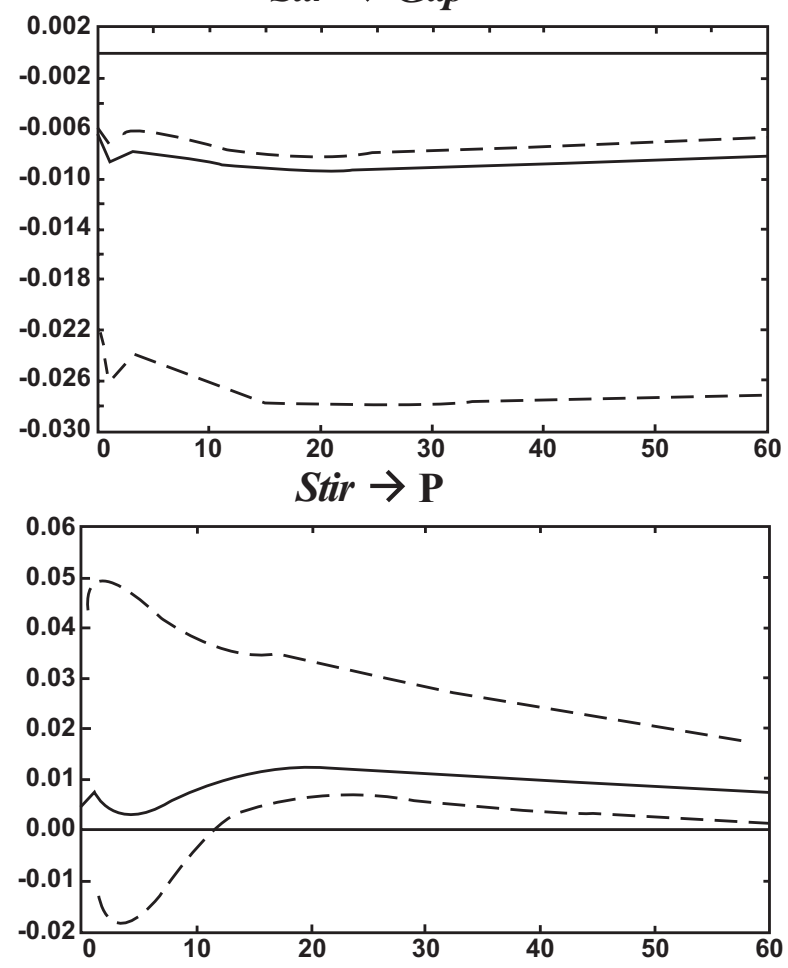


\section{Short-term responses}

Fig. (3). Impulse response functions (Transmission variable: Dcred).

\section{Short-term responses}

Fig. (4). Impulse response functions (Transmission variable: Rer).
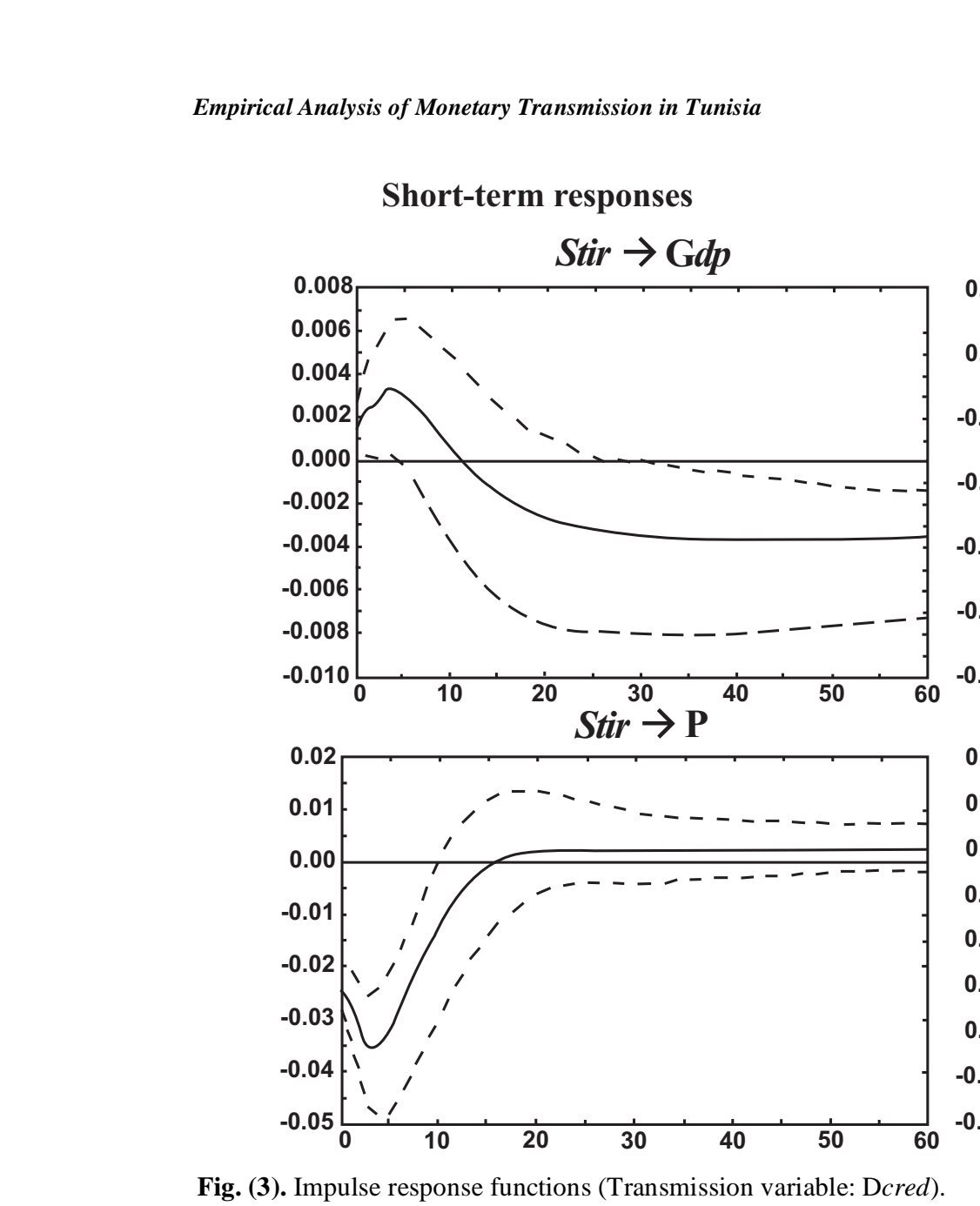

\section{Long-term responses}
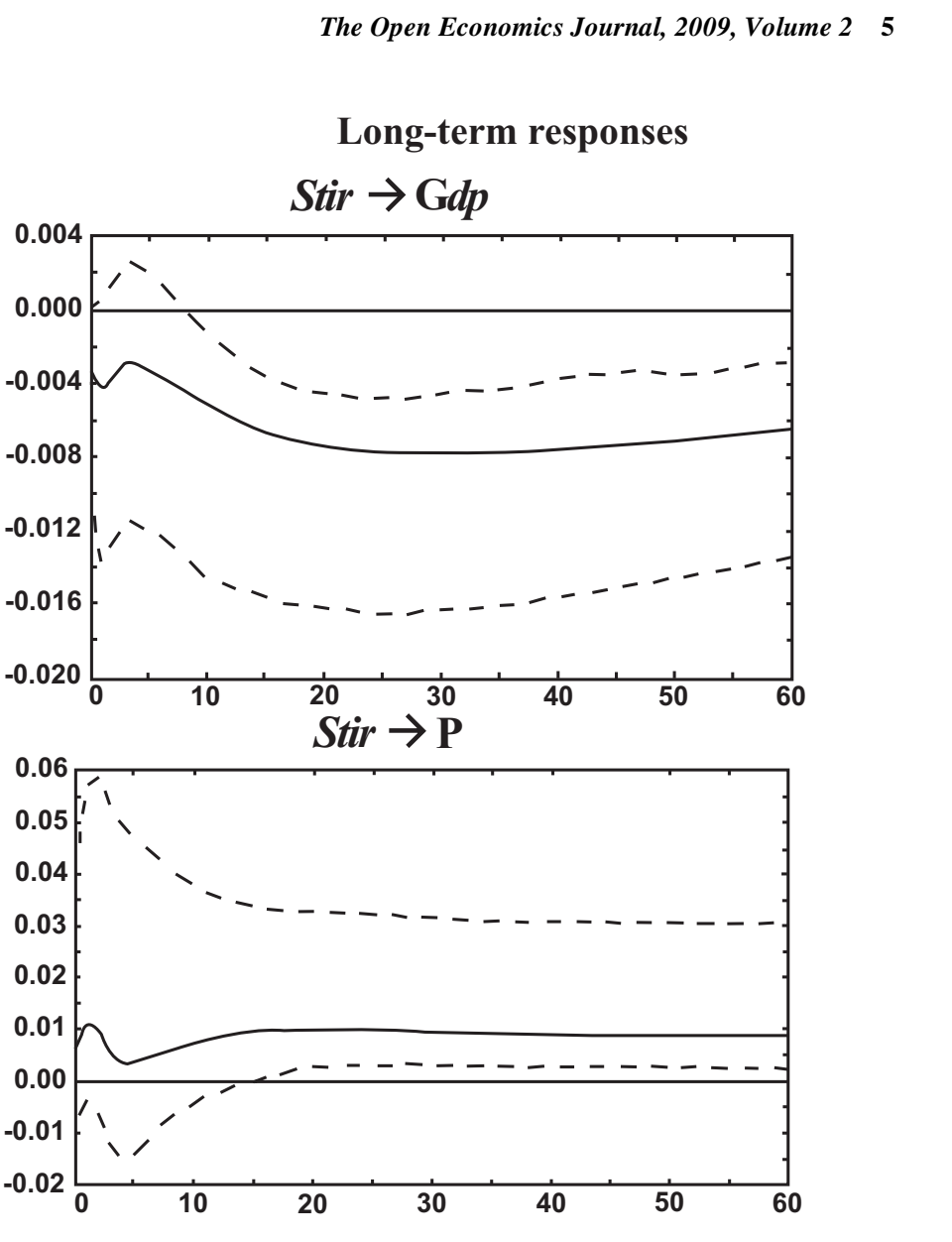

(1)

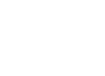

(a)
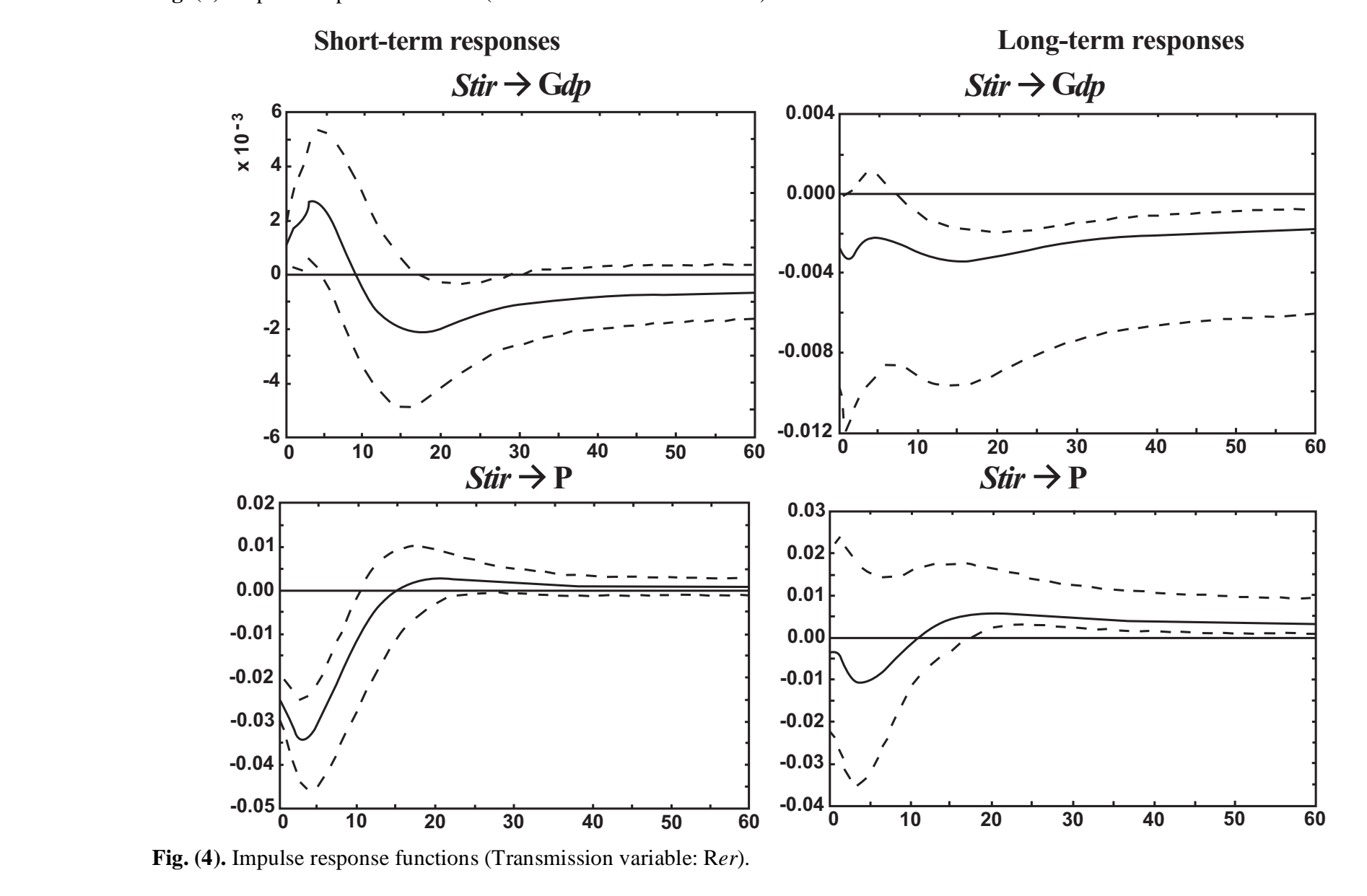

Long-term responses
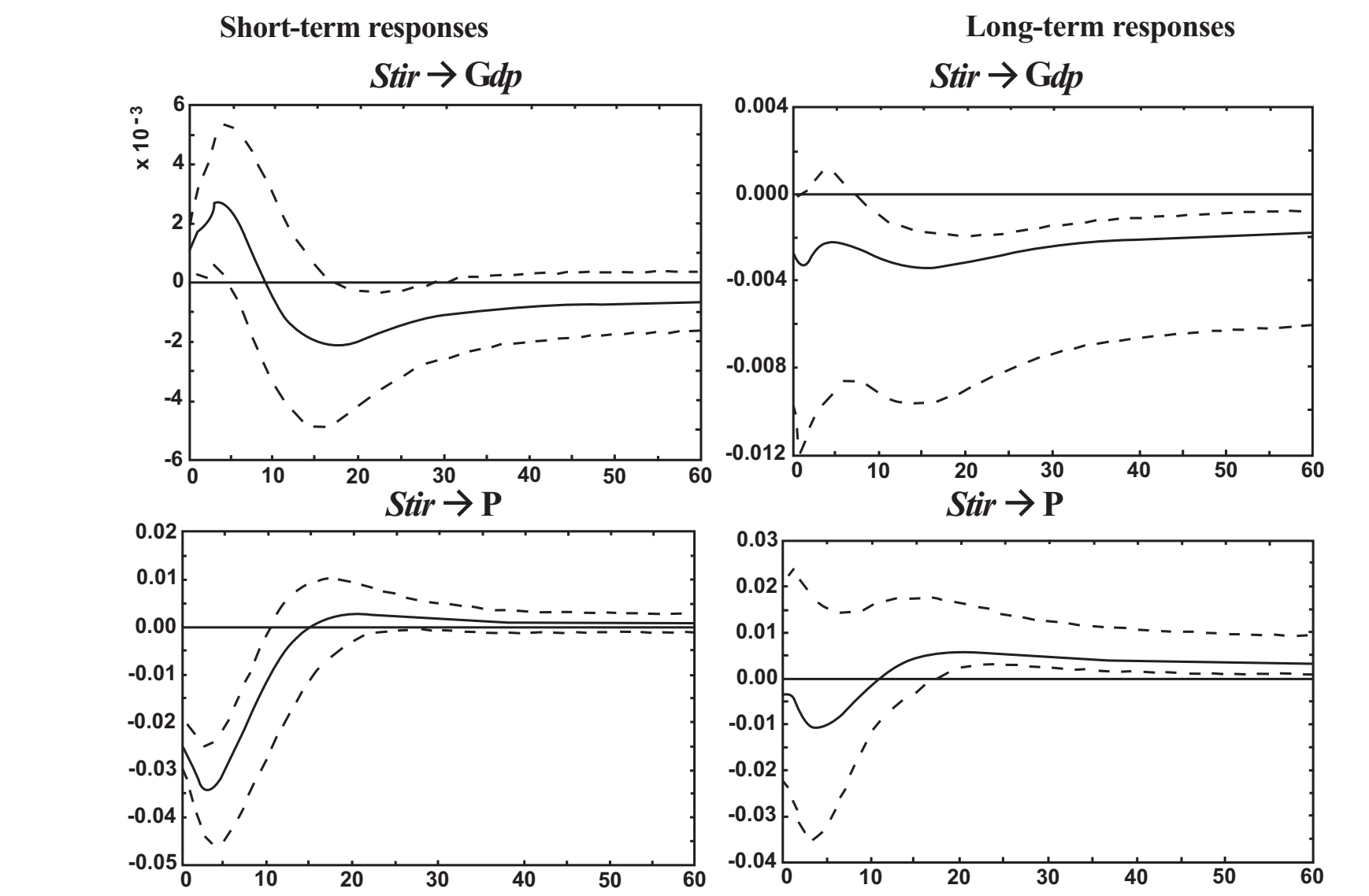

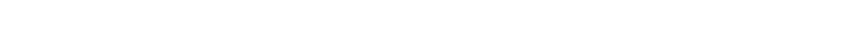

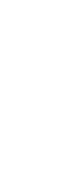


authorities still implement a more flexible exchange rate regime that has slowed down the price increase since August 2006. Besides, cautious monetary policy - the central bank has already raised its required reserves ratio - and the intention to take further action if necessary, are expected to keep inflation down to 4 percent on average. This expectation also takes into account the probable increase in the price of administered goods if international prices remain high.

Owing to a growing openness degree, managing the stability of the national currency external value does become more accurate. Coordination between monetary and exchange policies should be enhanced.

* A change in the short-term interest rate transitorily affects the inflation through various channels. During the first six months, a negative peak in the inflation rate is noticed extending 5\% through the interest rate channel and 3.5\% through the credit channel in price or in volume.

The central bank of Tunisia has a good supervision over inflation thanks to a higher importance of its interest rate channel. The credit channel should be taken as a complementary channel to the interest rate one.

Strong economic growth coupled with vigilant supervision should strengthen the financial position of banks. In this favorable environment, it is important to pursue efforts to reduce non-performing loans. Banking sector reforms like the recent privatization of the Tuniso-Kuwaiti Bank do continue. However, the banking sector remains fragmented. Considering heightened competitive pressures, its consolidation would be beneficial. As a recent legal obligation, the quality of the banking services has improved and the authorities are committed to conform the international standards.

Although most of the necessary legal and regulatory reforms are now in place in Tunisia, the challenge is to ensure that the financial systems fully operate according to market mechanisms underpinned by deregulation and increased competition among financial institutions. Thus, other longer-term reforms should aim at enhancing the mobilization of domestic savings and the deepening of financial markets.
Jbili, Enders and Trechel [18] notice that correlations between the private saving and some financial indicators (the ratios $\mathrm{M} 2$ aggregate on $\mathrm{G} d p$, monetary reserve on deposits, Dcred and the real interest rate) suggest that financial sector reforms have encouraged the private saving. Morrisson and Talbi [19], Goldsbrough, Coorey, Dicks-Mireaux, Horvath, Kohhkar, Mecagni, Offerdal and Zhou [20] find that the total factor productivity improves following the reforms. It gives evidence of a better factor allocation.

Besides, reforms to simplify the design of government paper should help strengthen secondary markets for government paper and provide meaningful yield curves. This, in turn, should facilitate the use of open market operations for the central bank. In addition, the remaining mandatory lending requirements should be abolished and interest rates fully liberalized.

\section{CONCLUSION}

This paper uses impulse response functions from a SVAR methodology in order to emphasize monetary transmission in a Maghreb country.

On the one hand, we deduce from a structural analysis that the exchange rate channel does not yet play an important role in the Tunisian monetary policy transmission. On the other hand, the national central bank should adopt an inflation targeting based on the long-term interest rate as the main intermediate variable, despite the complementarity with the credit variables.

This strategy should find convenient financial reforms as a companion to insure a good monetary regulation favorable to a more stable growth and macroeconomic environment.

Nevertheless, to improve the ability of central bankers to better manage the monetary transmission, the focus on the right intermediate variable or the privileged transmission channel should be redefined through time. That is the reason why a consistent extension should be based on a more timevarying SVAR approach. Besides, this extension does integrate the asset prices and the announcement effect channels that remain to be analyzed.

\section{APPENDIX}

We display as follows the structural parameter estimates of the A and B matrices using a SVAR AB models with contemporaneous restrictions. We report in brackets the standard errors of parameters.

\section{System 1}

$\hat{A}_{1}=\left(\begin{array}{ccc}1 & 0 & 0 \\ (0) & (0) & (0) \\ -0.5053 & 1 & -0.0744 \\ (0.0218) & (0) & (0.2108) \\ 0 & -0.0294 & 1 \\ (0) & (0.0158) & (0)\end{array}\right)$

$\hat{B}_{1}=\left(\begin{array}{ccc}0.0666 & 0 & 0 \\ (0.0031) & (0) & (0) \\ 0 & 0.0218 & 0 \\ (0) & (0.0031) & (0) \\ 0 & 0 & 0.0018 \\ (0) & (0) & (0.0004)\end{array}\right)$

System 2

$\hat{A}_{2}=\left(\begin{array}{ccc}1 & 0 & 0 \\ (0) & (0) & (0) \\ -0.4924 & 1 & 0.0330 \\ (0.0347) & (0) & (0.0756) \\ 0 & 0.7200 & 1 \\ (0) & (0.0428) & (0)\end{array}\right)$

$\hat{B}_{2}=\left(\begin{array}{ccc}0.0663 & 0 & 0 \\ (0.0031) & (0) & (0) \\ 0 & 0.0213 & 0 \\ (0) & (0.0015) & (0) \\ 0 & 0 & 0.0217 \\ (0) & (0) & (0.0010)\end{array}\right)$


System 3

$\hat{A}_{3}=\left(\begin{array}{ccc}1 & 0 & 0 \\ (0) & (0) & (0) \\ -0.4532 & 1 & -0.3005 \\ (0.0163) & (0) & (0.15) \\ 0 & -0.0310 & 1 \\ (0) & (0.0174) & (0)\end{array}\right) \quad \hat{B}_{3}=\left(\begin{array}{ccc}0.0663 & 0 & 0 \\ (0.0031) & (0) & (0) \\ 0 & 0.0162 & 0 \\ (0) & (0.0008) & (0) \\ 0 & 0 & 0.0080 \\ (0) & (0) & (0.0004)\end{array}\right)$

System 4

$\hat{A}_{4}=\left(\begin{array}{ccc}1 & 0 & 0 \\ (0) & (0) & (0) \\ -0.4280 & 1 & 0.0695 \\ (0.0234) & (0) & (0.0487) \\ 0 & 0.7924 & 1 \\ (0) & (0.0502) & (0)\end{array}\right) \quad \hat{B}_{4}=\left(\begin{array}{ccc}0.0959 & 0 & 0 \\ (0.031) & (0) & (0) \\ 0 & 0.0155 & 0 \\ (0) & (0.0010) & (0) \\ 0 & 0 & 0.0227 \\ (0) & (0) & (0.0011)\end{array}\right)$

System 5

$\hat{A}_{5}=\left(\begin{array}{ccc}1 & 0 & 0 \\ (0) & (0) & (0) \\ -0.4512 & 1 & -0.0130 \\ (0.0247) & (0) & (0.0756) \\ 0 & 0.5200 & 1 \\ (0) & (0.0125) & (0)\end{array}\right) \quad \hat{B}_{5}=\left(\begin{array}{ccc}0.0963 & 0 & 0 \\ (0.0325) & (0) & (0) \\ 0 & 0.0113 & 0 \\ (0) & (0.0255) & (0) \\ 0 & 0 & 0.0164 \\ (0) & (0) & (0.0250)\end{array}\right)$

System 6

$\hat{A}_{6}=\left(\begin{array}{ccc}1 & -0.2732 & 0 \\ (0) & (0.5744) & (0) \\ 0 & 1 & 0.0115 \\ (0) & (0) & (0.0246) \\ 0.3549 & 0 & 1 \\ (0.0268) & (0) & (0)\end{array}\right) \quad \hat{B}_{6}=\left(\begin{array}{ccc}0.0660 & 0 & 0 \\ (0.0031) & (0) & (0) \\ 0 & 0.0100 & 0 \\ (0) & (0.0005) & (0) \\ 0 & 0 & 0.0268 \\ (0) & (0) & (0.0013)\end{array}\right)$

System 7

$\hat{A}_{7}=\left(\begin{array}{ccc}1 & 0.8764 & 0 \\ (0) & (2.0160) & (0) \\ 0 & 1 & 0.016 \\ (0) & (0) & (0.0181) \\ -0.0149 & 0 & 1 \\ (0.0079) & (0) & (0)\end{array}\right) \quad \hat{B}_{7}=\left(\begin{array}{ccc}0.0664 & 0 & 0 \\ (0.0031) & (0) & (0) \\ 0 & 0.0022 & 0 \\ (0) & (0.0001) & (0) \\ 0 & 0 & 0.0080 \\ (0) & (0) & (0.0004)\end{array}\right)$

System 8

$\hat{A}_{8}=\left(\begin{array}{ccc}1 & -3.5327 & 0 \\ (0) & (2.815) & (0) \\ 0 & 1 & -0.0135 \\ (0) & (0) & (0.0056) \\ 0.3698 & 0 & 1 \\ (0.0285) & (0) & (0)\end{array}\right) \quad \hat{B}_{8}=\left(\begin{array}{ccc}0.0667 & 0 & 0 \\ (0.0032) & (0) & (0) \\ 0 & 0.0022 & 0 \\ (0) & (0.0001) & (0) \\ 0 & 0 & 0.0271 \\ (0) & (0) & (0.0013)\end{array}\right)$

We report as follows the structural estimates of $\mathrm{A}^{\prime}$ and $\mathrm{B}^{\prime}$ with short and long term restrictions using a SVAR Blanchard and Quah model.

System 1

$$
\hat{A}_{1}{ }^{\prime}=\left(\begin{array}{ccc}
0.0309 & 0.0112 & 0.0558 \\
(0.0212) & (0.0240) & (0.0346) \\
1.4592 * & 0.4664 * & 1.6135 * \\
0.0173 & 0.0262 & 0.0232 \\
(0.0132) & (0.0105) & (0.0180) \\
1.3134 * & 2.4978 * & 1.2874 * \\
-0.0063 & 0.0024 & 0.0042 \\
(0.0050) & (0.0029) & (0.0021) \\
-1.2815 * & 0.8266 * & 1.9588 *
\end{array}\right) \quad \hat{B}_{1}{ }^{\prime}=\left(\begin{array}{ccc}
4.6053 & 0 & 0 \\
(14.4407) & (0) & (0) \\
0.3189 * & 0 * & 0 * \\
2.9838 & 0.6163 & 0 \\
(10.6693) & (0.2969) & (0) \\
0.2797 * & 2.0761 * & 0 * \\
-2.9793 & -0.2067 & 0.3868 \\
(8.3766) & (0.2591) & (0.1770) \\
-0.3410 * & -0.7977 * & 2.1858 *
\end{array}\right)
$$


System 2

$\hat{A}_{2}{ }^{\prime}=\left(\begin{array}{ccc}0.0362 & 0.0410 & -0.0340 \\ (0.0172) & (0.0212) & (0.0295) \\ 2.0998 * & 1.9346 * & -1.1519 * \\ 0.0017 & 0.0338 & -0.0190 \\ (0.0144) & (0.0111) & (0.0149) \\ 0.1161 * & 3.0388 * & -1.2731 * \\ 0.0051 & -0.0150 & 0.0315 \\ (0.0165) & (0.0122) & (0.0111) \\ 0.3057 * & -1.2349 * & 2.8453 *\end{array}\right) \quad \hat{B}_{2}{ }^{\prime}=\left(\begin{array}{ccc}1.0634 & 0 & 0 \\ (1.2152) & (0) & (0) \\ 0.8751 * & 0 * & 0 * \\ 0.4263 & 0.5375 & 0 \\ (0.7728) & (0.2072) & (0) \\ 0.5516 * & 2.5942 * & 0 * \\ 0.9640 & -0.3411 & 0.9900 \\ (1.4290) & (0.5293) & (0.4884) \\ 0.6746 * & -0.6444 * & 2.0270 *\end{array}\right)$

System 3

$\hat{A}_{3}{ }^{\prime}=\left(\begin{array}{ccc}0.0281 & 0.0407 & 0.0412 \\ (0.0214) & (0.0352) & (0.0189) \\ 1.3099 * & 1.1565 * & 2.1803 * \\ 0.0070 & 0.0311 & 0.0105 \\ (0.0156) & (0.0166) & (0.0090) \\ 0.4485 * & 1.8743 * & 1.1730 * \\ -0.0065 & 0.0018 & 0.0014 \\ (0.0049) & (0.0027) & (0.0017) \\ -1.3393 * & 0.6672 * & 2.4703 *\end{array}\right) \quad \hat{B}_{3}{ }^{\prime}=\left(\begin{array}{cccc}3.7836 & 0 & 0 \\ (74.4120) & (0) & (0) \\ 0.0508 * & 0 * & 0 * \\ -0.4896 & 0.6354 & 0 \\ (12.5197) & (0.3496) & (0) \\ -0.0391 * & 1.8173 * & 0 * \\ -2.2481 & 0.4433 & 0.1272 \\ (26.5027) & (0.2807) & (0.0402) \\ -0.0848 * & 1.5791 * & 3.1655 *\end{array}\right)$

\section{System 4}

$\hat{A}_{4}{ }^{\prime}=\left(\begin{array}{ccc}0.0281 & 0.0407 & 0.0412 \\ (0.0216) & (0.0341) & (0.0178) \\ 1.3003 * & 1.1945 * & 2.3131 * \\ 0.0070 & 0.0311 & 0.0105 \\ (0.0151) & (0.0160) & (0.0087) \\ 0.4663 * & 1.9380 * & 1.2110^{*} \\ -0.0065 & 0.0018 & 0.0041 \\ (0.0050) & (0.0027) & (0.0016) \\ -1.3144 * & 0.6753 * & 2.5900 *\end{array}\right) \quad \hat{B}_{4}{ }^{\prime}=\left(\begin{array}{ccc}3.7836 & 0 & 0 \\ (11.6646) & (0) & (0) \\ 0.3244 * & 0 * & 0 * \\ -0.4896 & 0.6354 & 0 \\ (20.2545) & (0.4130) & (0) \\ -0.0242 * & 1.5384 * & 0 * \\ -2.2481 & 0.4433 & 0.1272 \\ (9.0922) & (0.3202) & (3.2241) \\ -0.2473 * & 1.3842 * & 3.2241^{*}\end{array}\right)$

\section{System 5}

$\hat{A}_{5}{ }^{\prime}=\left(\begin{array}{ccc}0.0480 & 0.0408 & 0.0150 \\ (0.0137) & (0.0259) & (0.0208) \\ 3.4959 * & 1.5760 * & 0.7226 * \\ -0.0058 & 0.0068 & 0.0023 \\ (0.0040) & (0.0014) & (0.0030) \\ -1.4514 * & 4.6857 * & 0.7525 * \\ 0.0032 & 0.0029 & 0.0066 \\ (0.0030) & (0.0022) & (0.0023) \\ 1.0734 * & 1.3235 * & 2.8956 *\end{array}\right) \quad \hat{B}_{5}{ }^{\prime}=\left(\begin{array}{ccc}1.9942 & 0 & 0 \\ (15.8694) & (0) & (0) \\ 0.1257 * & 0 * & 0 * \\ -0.7346 & 0.2373 & 0 \\ (4.6485) & (0.0837) & (0) \\ -0.1580 * & 2.8346 * & 0 * \\ -0.8062 & 0.2524 & 0.1195 \\ (5.7091) & (0.1056) & (0.0592) \\ -0.1412 * & 2.3905 * & 2.0180 *\end{array}\right)$

\section{System 6}

$\hat{A}_{6}{ }^{\prime}=\left(\begin{array}{ccc}0.0421 & 0.0173 & -0.0449 \\ (0.0150) & (0.0281) & (0.0238) \\ 2.8094 * & 0.6168 * & -1.8887 * \\ 0.0135 & 0.0229 & -0.0197 \\ (0.0112) & (0.0138) & (0.0108) \\ 1.2079 * & 1.6565 * & -1.8196 * \\ 0.0047 & -0.0155 & 0.0312 \\ (0.0155) & (0.0166) & (0.0077) \\ 0.3062 * & -1.3285 * & 4.0297 *\end{array}\right) \quad \hat{B}_{6}{ }^{\prime}=\left(\begin{array}{ccc}1.2341 & 0 & 0 \\ (6.5487) & (0) & (0) \\ 0.1885 * & 0 * & 0 * \\ 0.1847 & 0.5990 & 0 \\ (1.8290) & (0.2967) & (0) \\ 0.1010 * & 2.0188 & 0 * \\ 1.0546 & -0.9672 & 0.6098 \\ (5.5995) & (0.5949) & (0.2640) \\ 0.1883 * & -1.6257 * & 2.3099 *\end{array}\right)$

System 7

$\hat{A}_{7}{ }^{\prime}=\left(\begin{array}{ccc}0.0213 & 0.0253 & -0.0129 \\ (0.009) & (0.0121) & (0.0198) \\ 2.6294 * & 1.548 * & 2.5187 * \\ 0.0135 & 0.0229 & -0.0197 \\ (0.0112) & (0.052) & (0.006) \\ 1.1079 * & 1.005 * & 2.3696 * \\ 0.0127 & 0.005 & 0.0112 \\ (0.0119) & (0.0596) & (0.0787) \\ 0.3862 * & 1.255 * & 2.3697 *\end{array}\right) \quad \hat{B}_{7}{ }^{\prime}=\left(\begin{array}{ccc}-1.00541 & 0 & 0 \\ (0.0487) & (0) & (0) \\ 1.987 * & 0 * & 0 * \\ -0.1847 & 0.690 & 0 \\ (0.8290) & (0.0958) & (0) \\ 0.1010 * & 2.0188 & 0 * \\ 1.0546 & 0.9642 & 0.0018 \\ (4.025) & (0.560) & (0.0960) \\ 0.1302 * & -1.057 * & 1.020 *\end{array}\right)$




\section{System 8}

$\hat{A}_{8}{ }^{\prime}=\left(\begin{array}{ccc}0.0405 & -0.0454 & 0.0215 \\ (0.0205) & (0.0185) & (0.0162) \\ 1.9801 * & * 2.4605 * & 1.3290 * \\ 0.0014 & 0.0016 & 0.0004 \\ (0.0010) & (0.0005) & (0.0005) \\ 1.3821 * & 2.8583 * & 0.8864 * \\ -0.0027 & -0.0003 & 0.0073 \\ (0.0026) & (0.0019) & (0.0009) \\ -1.0404 * & -0.1644 * & 7.9348 *\end{array}\right) \quad \hat{B}_{8}{ }^{\prime}=\left(\begin{array}{ccc}1.8652 & 0 & 0 \\ (9.0289) & (0) & (0) \\ 0.2066^{*} & 0 * & 0 * \\ 0.6794 & 0.3040 & 0 \\ (4.6767) & (0.1229) & (0) \\ 0.1453 * & 2.4733^{*} & 0 * \\ -0.7486 & -0.2819 & 0.1154 \\ (4.7483) & (0.1278) & (0.0357) \\ -0.1577 * & -2.2056 * & 3.2343 *\end{array}\right)$

\section{REFERENCES}

[12] Ganev G, Molnar K, Rybinski K, Wozniak P. Transmission mechanism of monetary policy in Central and Eastern Europe. Warsaw: CASE; 2002 (Center for Social and Economic Research, Report No. 52).

[1] Bernanke BS, Gertler M. Inside the black box: The credit channel of monetary policy transmission. J Econ Persp 1995; 9: 27-48.

[2] Meltzer AH. Monetary, credit (and other) transmission processes: A monetarist perspective. J Econ Persp 1995; 9: 49-72.

[3] Mishkin FS. Symposium on the monetary transmission mechanism. J Econ Persp 1995; 9: 3-10.

[4] Taylor JB. The monetary transmission mechanism: An empirical framework. J Econ Persp 1995; 9: 11-26.

[5] Chaabane A, Hachicha A. Monetary policy transmission mechanism in Tunisia. Euro-Mediter Econ Financ Rev 2007; 6: 104-26.

[6] Fry R, Pagan A. Some issues in using VARs for macroeconometric research. CAMA Working Paper 2005; p. 19.

[7] Amisano G, Giannini C. Topics in structural VAR econometrics. Berlin \& Heidelberg, Germany: Springer-Verlag 1997.

[8] Blanchard JO, Quah D. The dynamic effects of aggregate demand and supply disturbances. Am Econ Rev 1989; 79: 655-73.

[9] Mehrotra AN. Exchange and interest rate channels during a deflationary era - Evidence from Japan, Hong Kong and China. J Comp Eco 2007; 35: 188-210.

[10] Breitung J, Bruggemann R, Lütkepohl H. Structural vector autoregressive modelling and impulse responses. In: Lütkepohl $\mathrm{H}$, Kratzig M. Eds. Applied time series econometrics. Cambridge: Cambridge University Press 2004; pp. 159-96.

[11] Hall P. The bootstrap and Edgeworth expansion. New York, USA: Springer-Verlag 1992

[13] Kim S, Roubini N. Exchange rate anomalies in the industria countries: A solution with a structural VAR approach. J Monet Econ 2000; 45: 561-86.

[14] Leeper EM, Roush JE. Putting ' $M$ ' back in monetary policy. J Money Cred Bank 2003; 35: 1217-56.

[15] Mojon B, Peersman G. A VAR description of the effects of monetary policy in the individual countries of the Euro area. In: Angeloni I, Kashyap A, Mojon B. Eds. Monetary Policy transmission in the Euro area, Cambridge: Cambridge University Press 2003; pp. 56-74.

[16] Dedola L, Lippi F. The monetary transmission mechanism: Evidence from the industry data of five OECD countries. Eur Econ Rev 2005; 49: 1543-69.

[17] Benkwitz A, Lütkepohl H, Wolters J. Comparison of bootstrap confidence intervals for impulse responses of German monetary systems. Macro Dynam 2001; 5: 81-100.

[18] Jbili A, Enders K, Trechel V. Financial sector reforms in Morocco and Tunisia. Fin Dev 1997; 34: 29-31.

[19] Morrisson C, Talbi B. Long-Term Growth in Tunisia. Paris: OECD 1996.

[20] Goldsbrough DJ, Coorey S, Dicks-Mireaux L, et al. Reinvigorating Growth in Developing Countries: Lessons from Adjustment Policies in Eight Economies. Washington DC: International Monetary Fund 1996.

(C) Bates and Hachicha; Licensee Bentham Open

This is an open access article licensed under the terms of the Creative Commons Attribution Non-Commercial License (http://creativecommons.org/licenses/bync/3.0/) which permits unrestricted, non-commercial use, distribution and reproduction in any medium, provided the work is properly cited. 